\title{
La obesidad, un raro padecimiento en los insectos
}

\author{
Daniel González-Tokman
}

\section{Resumen}

La obesidad no es exclusiva de los humanos y sus mascotas. Los animales silvestres, incluidos los insectos, también pueden ser víctimas de este padecimiento. Sin embargo, los casos de obesidad en insectos son pocos y no siempre se deben a la mala alimentación y a la falta de actividad, sino que se pueden asociar al parasitismo.

Los insectos tienen mecanismos que les impiden ser obesos y no todos tienen la capacidad de almacenar una gran cantidad de energía, en forma de grasa. En los humanos, en cambio, la habilidad de almacenar mucha grasa que ahora representa un problema de salud pública, pudo ser benéfica durante la evolución de nuestra especie debido a los altos requerimientos energéticos de nuestro enorme cerebro en un ambiente donde no existía certeza de encontrar alimento.

Palabras clave: evolución, grasa, insecto, obesidad, parasitismo

\section{ObESITY, A RARE PROBLEM IN INSECTS}

\begin{abstract}
Obesity is not exclusive from humans and their pets. Wild animals, including insects, can also suffer from this disease. However, the evidence of obesity in insects is scarce and it is not always related to bad feeding habits and low physical activity, but it could be related to parasitism. Insects bear mechanisms that prevent them from becoming obese and not all of them have the capacity to store big amounts of fat as an energy supply. In humans, in contrast, the ability to store large amounts of fat, which now represents a severe public health issue, could have been beneficial during the evolution of our species. This was due to the extremely high energetic requirements of our big brain in an environmental context where food was not always accessible.
\end{abstract}

Keywords: evolution, fat, insect, obesity, parasitism

Dol: http://doi.org/10.22201/codeic.16076079e.2020.v21n2.a2 


\section{Daniel González-Tokman}

daniel.gt@inecol.mx https://orcid.org/0000-0001-7251-5773

El Dr. Daniel González Tokman es investigador Cátedra conacyt En el Instituto de Ecología A. C. de Xalapa, Veracruz, desde 2014. Es Doctor en Ciencias Biológicas por la Universidad Nacional Autónoma de México y realizó estudios posdoctorales en la Universidad Autónoma del Estado de Morelos. Ha realizado estancias de investigación en la Universidad de Carleton, Canadá, la Universidad Macquarie, Australia, y la Universidad de Zurich, Suiza. Desde el año 2014 pertenece al Sistema Nacional de Investigadores. Sus líneas de investigación incluyen evolución, ecología, fisiología, comportamiento y conservación de insectos. 
Imagen 1. Persona con obesidad. Tomado de wikipedia. org (licencia Creative Commons Attribution 3.0)

\section{Introducción}

De acuerdo con la Organización para la Cooperación y el Desarrollo Económicos (OCDE), vivimos en uno de los países con mayor índice de obesidad en el mundo (2017), donde tres de cada diez mexicanos tienen sobrepeso, lo cual representa un grave problema de salud pública (ver imagen 1). Las principales causas de la obesidad son el consumo excesivo de calorías y el poco gasto físico, que ocasionan un balance energético positivo, es decir, mayor ganancia que pérdida de calorías. Sin embargo, los humanos no somos los únicos animales obesos. Los macacos que fueron introducidos del continente asiático a una isla de la laguna de Catemaco, Veracruz, en el corazón de la selva de los Tuxtlas, son gordos debido a las cantidades excesivas de alimento que reciben de los turistas y a su poca actividad física. Nuestras mascotas también pueden ser obesas; de hecho, más de la mitad de los perros y gatos en los Estados Unidos lo son, e incluso padecen enfermedades como diabetes tipo 2 (DeGodoy y Swanson 2013).

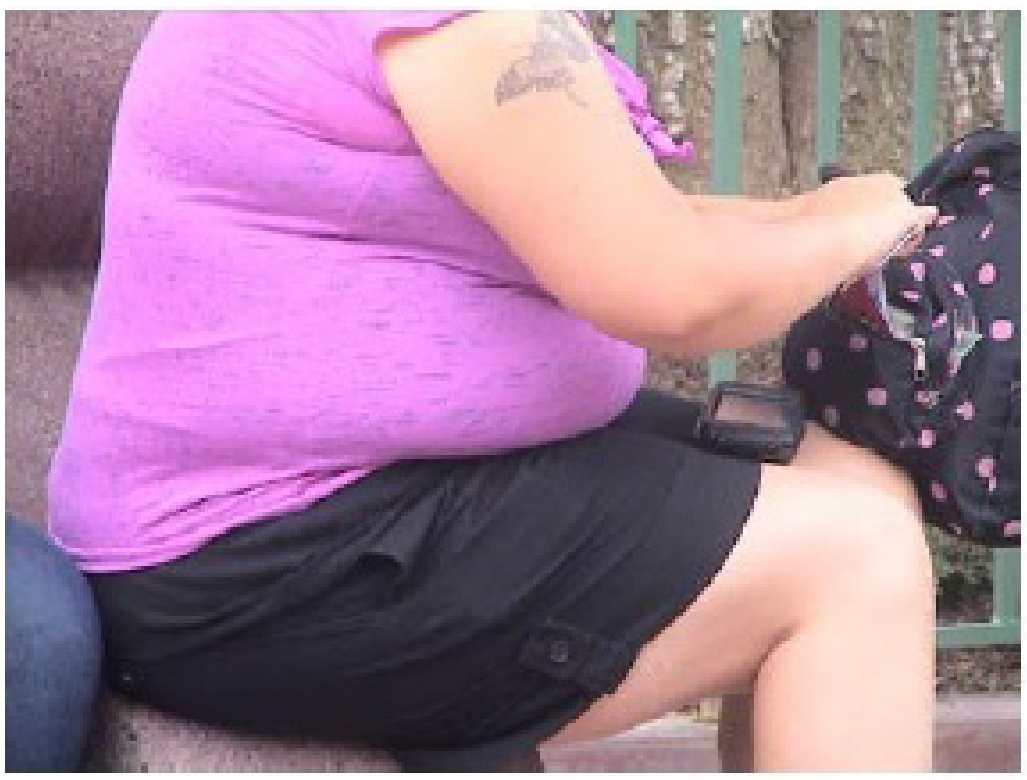

Según la Organización Mundial de la Salud, la obesidad se define como una acumulación anormal o excesiva de grasa que puede ser perjudicial para la salud. Pero si queremos extender el concepto de obesidad a todos los animales, debemos entenderla como una acumulación de grasa corporal tal que reduce las probabilidades de supervivencia y reproducción de un individuo.

Está claro que en humanos y animales domésticos la obesidad representa un problema, pero ¿qué hay de los animales silvestres? ¿Padecen obesidad? ¿No resulta conveniente almacenar grasa, tal vez a modo de preparación para momentos de escasez de alimento? 


\section{Obesidad en animales silvestres}

En los animales silvestres es difícil determinar si existe obesidad, pues esto requiere conocer los niveles de grasa corporal en la población y el umbral sobre el cual la acumulación de grasa reduce la longevidad y la reproducción de los individuos. Además, el alimento en animales que viven en condiciones naturales es casi siempre escaso y almacenar energía en forma de grasa puede resultar conveniente ante futuras condiciones de escasez (Bellisari, 2007).

Pero ¿quién ha visto un insecto obeso? ¿Existe tal cosa? La respuesta es positiva. Algunos insectos, no todos, pueden almacenar tanta grasa corporal que reduce su supervivencia y reproducción. En moscas de la fruta, obesas después de comer carbohidratos en exceso, la acumulación excesiva de grasa provoca una reducción en la longevidad. Sin embargo, a diferencia de los humanos y sus mascotas, la obesidad en los insectos no se aprecia a simple vista debido a que el tamaño corporal de los insectos se fija en el momento en el que emergen como adultos, con un duro exoesqueleto que carece de flexibilidad y no les permite crecer (Davidowitz et al. 2003).

La obesidad en insectos no necesariamente se debe a un consumo calórico excesivo o a una vida sedentaria. En las libélulas, los individuos se vuelven obesos cuando están infectados por unos parásitos del tracto digestivo llamados gregarinas. Las libélulas infectadas tienen dificultades para mover sus músculos de vuelo, acumulan el doble de carbohidratos en su sistema circulatorio y, sobre todo, almacenan más grasa en el cuerpo que los animales no infectados. Esto se debe en parte a que pierden la habilidad de utilizar la insulina para metabolizar los carbohidratos, que eventualmente se acumulan en forma de grasa (Schilder y Marden 2007) (ver imagen 2).

\section{La evolución y la obesidad}

Aunque existen casos de insectos obesos, éstos son pocos. Esto podría ser porque acumular grasa es una habilidad que no todos los animales han sido capaces de desarrollar a lo largo de su evolución. ${ }^{1}$ El metabolismo en los insectos ha sido seleccionado de modo que incluso se puede resistir la obesidad. Esto quiere decir que, después de muchas generaciones de enfrentarse a dietas con muchos carbohidratos, los insectos poseen mecanismos para no acumular grasa corporal a pesar de haber comido dietas ricas en azúcares. Esto se demostró en mariposas mediante un experimento de evolución en cautiverio.

Los investigadores de universidades de Inglaterra, Australia y Nueva Zelanda mantuvieron a un grupo de mariposas durante ocho generaciones alimentadas con una dieta rica en carbohidratos y pobre en proteínas. Durante las primeras generaciones, las mariposas que comieron esta dieta almacenaron una alta cantidad de lípidos, como nos sucede a los humanos cuando comemos dietas ricas en carbohidratos. Sin embargo, con el paso de las generaciones, las 
Imagen 2. Las libélulas Libellula pulchella se vuelven obesas cuando son parasitadas por gregarinas.

Imagen tomada de wikipedia.org con licencia de Creative Commons mariposas eran capaces de comer muchos carbohidratos sin almacenarlos en forma de grasa. Paralelamente, los investigadores alimentaron a otro grupo de mariposas con una dieta pobre en carbohidratos y rica en proteínas, también durante ocho generaciones. Éstas siempre tuvieron la habilidad de almacenar grasa cuando se les ofrecieron carbohidratos en la dieta. Este experimento, publicado en la prestigiosa revista de la Academia Nacional de Ciencias de los Estados Unidos, en el año 2006, demostró que la evolución puede seleccionar una resistencia a la obesidad en insectos. El costo que pagan las mariposas resistentes a la obesidad sería el riesgo de morir de inanición más rápidamente cuando el alimento sea escaso (Warbrick-Smith et al. 2006).

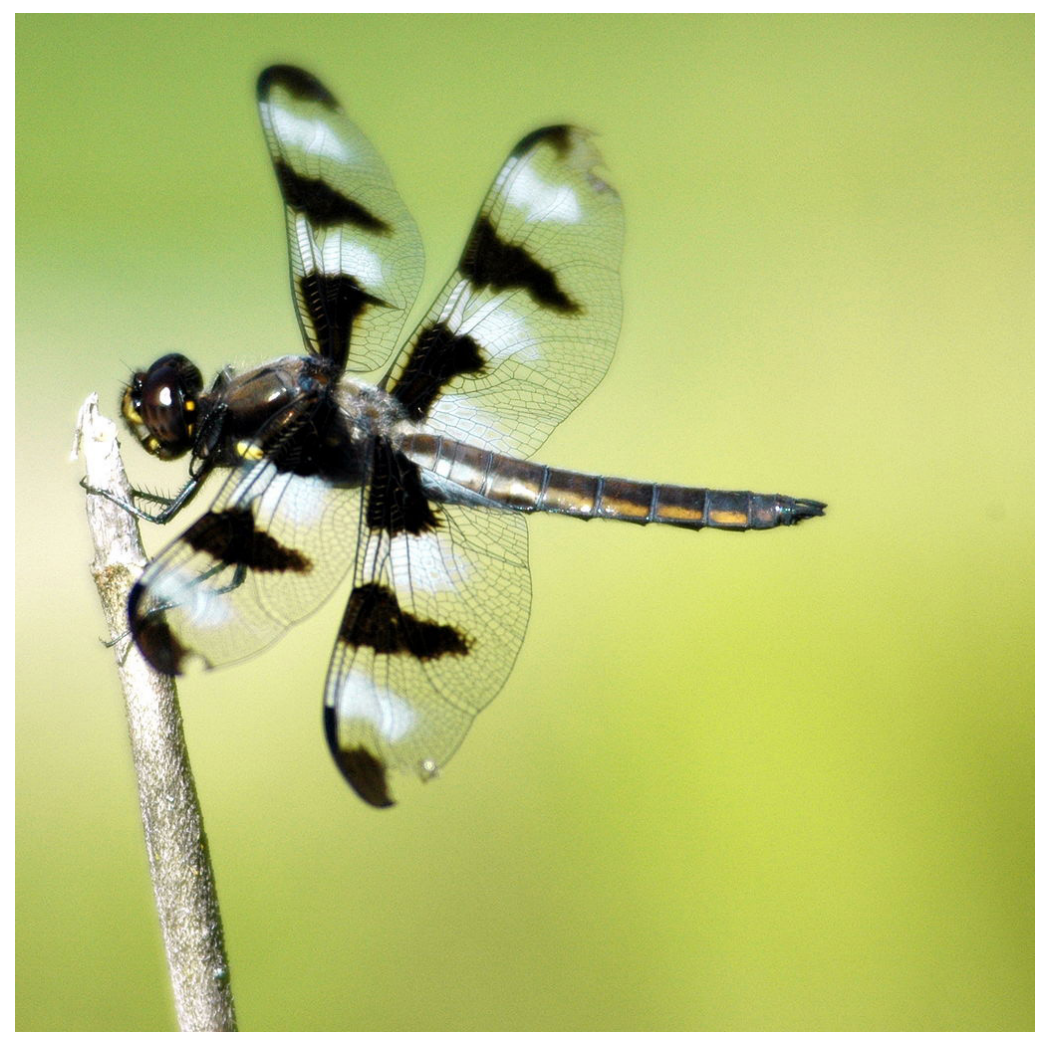

A diferencia de las mariposas del experimento, los humanos estamos mal adaptados metabólicamente para comer dietas ricas en carbohidratos. Necesitamos balancear el consumo de azúcares para evitar la obesidad y los costos que ésta implica en nuestra calidad de vida. En el pasado, cuando los humanos eran nómadas y no tenían certeza de encontrar alimento en todo momento, almacenar grasa pudo representar una adaptación fundamental para sobrevivir en tiempos de escasez. Esto se debe al alto gasto energético que demanda nuestro cerebro, que es significativamente más grande que el del resto de los homínidos (ya extintos) y, por lo tanto, requiere mayor cantidad de energía para funcionar. En un artículo sobre los orígenes evolutivos de la obesidad, publicado en 2007 por la Profesora Anna Bellisari, de Ohio, Estados Unidos, la obesidad en los humanos fue incluso descrita como el costo inevitable que paga la especie humana por tener un cerebro tan grande. 
Imagen 3. Las mariposas Plutella xylostella se pueden resistir a la obesidad a lo largo de las generaciones

Imagen tomada de commons. wikimedia.org con licencia de Creative Commons

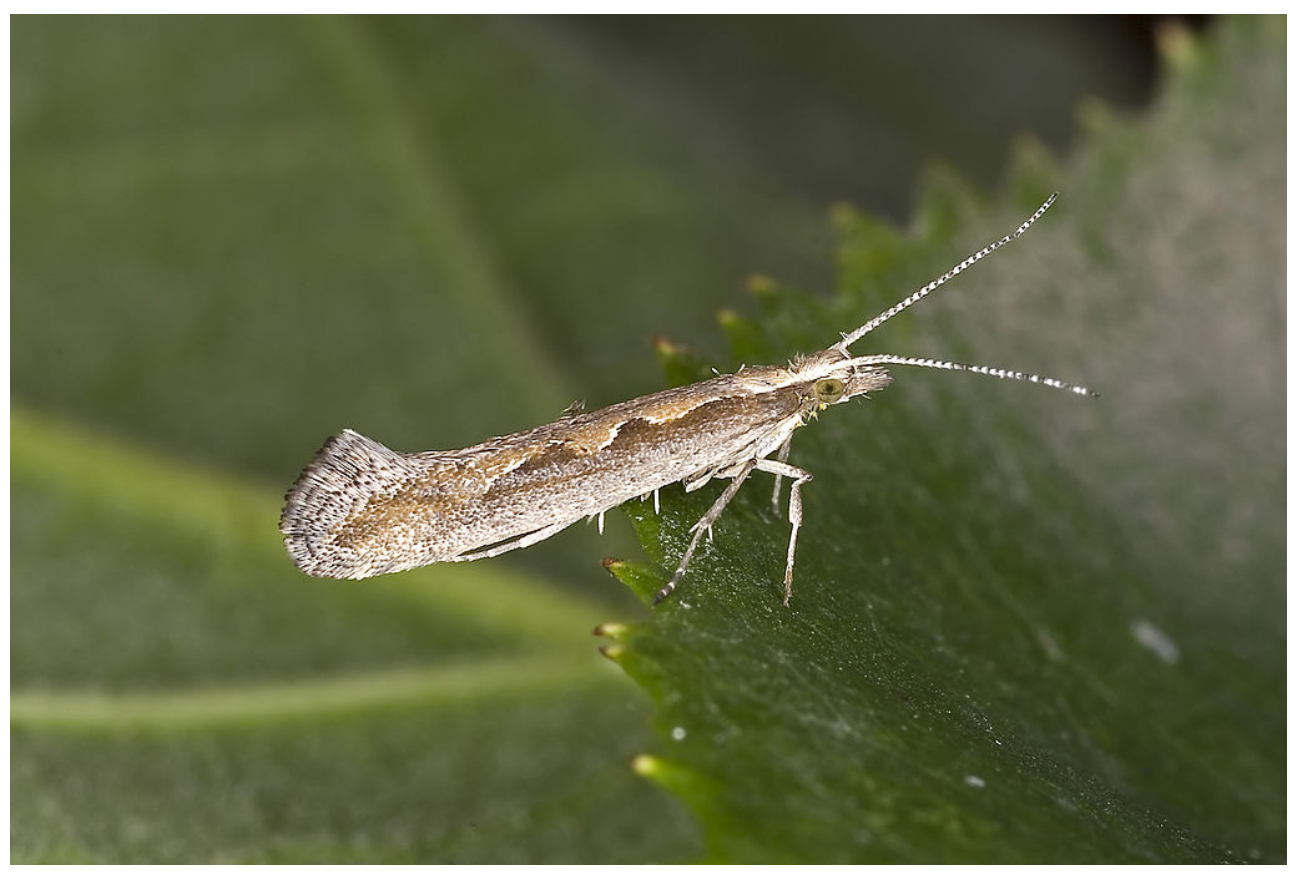

En la actualidad, comunidades humanas en sitios aislados de la sociedad industrializada se benefician de almacenar grasa en el cuerpo y muestran preferencias sexuales por parejas con una habilidad de adquirir recursos y almacenarlos en el cuerpo en forma de grasa. Lo que todavía no sabemos es si, con el paso de las generaciones, la evolución favorecerá en los humanos la selección de características que impidan la acumulación de grasa corporal, tal como sucede en los insectos.

\section{Referencias}

Bellisari, A. (2008). Evolutionary origins of obesity. Obesity reviews, 9(2), 165-180.

- De Godoy, M. R. C., \& Swanson, K. S. (2013). Companion animals symposium: Nutrigenomics: Using gene expression and molecular biology data to understand pet obesity. Journal of animal science, 91(6), 2949-2964.

- Davidowitz, G., D'Amico, L. J., \& Nijhout, H. F. (2003). Critical weight in the development of insect body size. Evolution \& development, 5(2), 188-197.

* GallupJr, G. G., \& Frederick, D. A. (2010). The science of sex appeal: An evolutionary perspective. Review of General Psychology, 14(3), 240.

* Organización para la Cooperación y el Desarrollo Económicos (OCDE) (2017). oCDE obesity update 2017. Recuperado de: http://www.oecd.org/health/obesityupdate.htm. 
* Schilder, R. J., \& Marden, J. H. (2007). Metabolic syndrome and obesity in an insect. Proceedings of the National Academy of Sciences, 103(49), 18805-18809.

* Skorupa, D. A., Dervisefendic, A., Zwiener, J., \& Pletcher, S. D. (2008). Dietary composition specifies consumption, obesity, and lifespan in Drosophila melanogaster. Aging cell, 7(4), 478-490.

* Warbrick-Smith, J., Behmer, S. T., Lee, K. P., Raubenheimer, D., \& Simpson, S. J. (2006). Evolving resistance to obesity in an insect. Proceedings of the National Academy of Sciences, 103(38), 14045-14049.

Who.int. (2020). WHO. Obesity. [en línea] Recuperado de: https://www.who.int/ topics/obesity/en/.

\section{Cómo citar este artículo}

* González-Tokman, Daniel (2020). La obesidad, un raro padecimiento en los insectos. Revista Digital Universitaria (RDU). Vol. 21, núm. 2 marzo-abril. Dol: http:// doi.org/10.22201/codeic.16076079e.2020.v21n2.a2.

Recepción: 07/11/2018. Aprobación: 23/08/2019 